Document downloaded from:

http://hdl.handle.net/10251/114603

This paper must be cited as:

Ali, M.; Ahmed, I.; Ramirez Hoyos, P.; Nasir, S.; Mafé, S.; Niemeyer, C.; Ensinger, W. (2018). Lithium Ion Recognition with Nanofluidic Diodes through Host-Guest Complexation in Confined Geometries. Analytical Chemistry. 90(11):6820-6826.

doi:10.1021/acs.analchem.8b00902

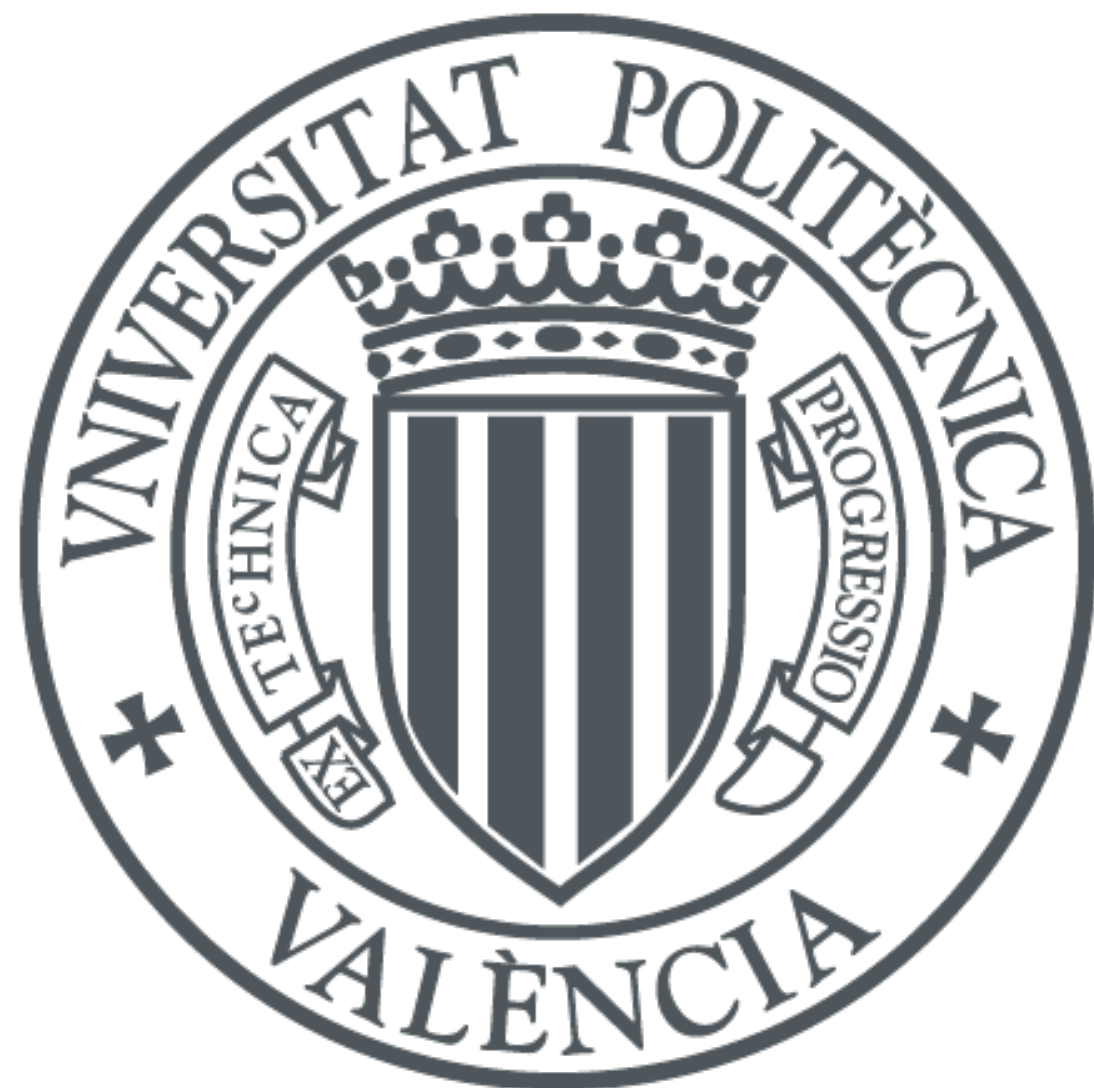

The final publication is available at

http://doi.org/10.1021/acs.analchem.8b00902

Copyright American Chemical Society

Additional Information

This document is the Accepted Manuscript version of a Published Work that appeared in final form in

Analytical Chemistry, copyright (C) American Chemical Society after peer review and technical editing by the publisher.

To access the final edited and published work see [insert ACS Articles on Request authordirected link to

Published Work, see http://doi.org/10.1021/acs.analchem.8b00902 


\title{
Lithium ion recognition with nanofluidic diodes through host-guest complexation in confined geometries
}

Mubarak Ali, ${ }^{\mathrm{a}, \mathrm{b}_{*}}$ Ishtiaq Ahmed, ${ }^{\mathrm{c}}$ Patricio Ramirez, ${ }^{\mathrm{d}}$ Saima Nasir, ${ }^{\mathrm{a}}$ Salvador Mafe, ${ }^{\mathrm{e}}$ Christof M. Niemeyer, ${ }^{c}$ and Wolfgang Ensinger ${ }^{a}$

${ }^{a}$ Technische Universität Darmstadt, Fachbereich Material- u. Geowissenschaften, Fachgebiet Materialanalytik, Alarich-Weiss-Str. 2, D-64287 Darmstadt, Germany

${ }^{b}$ GSI Helmholtzzentrum für Schwerionenforschung, Planckstr. 1, D-64291 Darmstadt, Germany

${ }^{c}$ Karlsruhe Institute of Technology (KIT), Institute for Biological Interfaces (IBG-1), Hermann-vonHelmholtz-Platz, D-76344 Eggenstein-Leopoldshafen, Germany

${ }^{d}$ Departament de Física Aplicada, Universitat Politécnica de València, E-46022 València, Spain

${ }^{e}$ Departament de Física de la Tierra i Termodinàmica, Universitat de València, E-46100 Burjassot, Spain.

*Corresponding author: E-mail address: M.Ali@gsi.de

\begin{abstract}
The lithium ion recognition is receiving significant attention because of its application in pharmaceuticals, lubricants, and, especially, in energy technology. We present a nanofluidic device for specific lithium ion recognition via host-guest complexation in a confined environment. A lithium-selective receptor molecule, the aminoethyl-benzo-12-crown-4 $\left(\mathrm{BC} 12 \mathrm{C} 4-\mathrm{NH}_{2}\right)$ is designed and functionalized on single conical nanopores in polyethylene terephthalate (PET) membranes. The native carboxylic acid groups on the pore walls are covalently linked with the crown ether moieties and the process is monitored from the changes in the current-voltage $(I-V)$ curves. The B12-crown-4 moieties are known to specifically bind with lithium ions
\end{abstract}


and when the modified pore is exposed to different alkali metal chloride solutions separately, significant changes in the ion current and rectification are only observed for lithium chloride. This fact suggests the generation of positively charged B12C4$\mathrm{Li}^{+}$complexes on the pore surface. Furthermore, the nanofluidic diode is able to recognize the lithium ion even in the presence of high concentrations of potassium ions in the external electrolyte solution. Thus, this nanodevice suggests a strategy to miniaturize nanofluidic porous systems for efficient recognition, extraction and separation of lithium from raw materials.

Keywords: synthetic nanopores; track-etching; chemical functionalization; host-guest interactions; crown ethers; electric current rectification. 


\section{Introduction}

Ion channel proteins control the trafficking of ions and molecules across the cell membrane and regulate a variety of biological functions including signal transmission and muscle contraction. ${ }^{1-4}$ The channels have the ability to discriminate between very similar ions and exhibit also unique characteristics such as gating and ion current rectification. ${ }^{1,2,5-8}$ In addition to ion selectivity, protein channels embedded in the membrane lipid bilayer allow for a variety of applications in nano and biotechnology such as sensing and manipulation of single molecules. ${ }^{9-11}$

The unique functionality and ionic selectivity of ion channels is partly due to the asymmetric distribution of amino acid residues. Inspired from nature, artificial analogues of biological ion channels with similar functionalities have been prepared. Track-etched conical nanopores have received great interest because of their mechanical stability, control over pore dimensions (size and geometry), and surface functionalization. ${ }^{12-14}$

In the particular case of polyethylene terephthalate (PET) membranes, the carboxylic acids groups generated on the pore surface can be easily functionalized with different molecules, leading to the modulation of the ionic transport and rectification characteristics. ${ }^{15-23}$ Moreover, the surface charge regulated phenomena can be implemented in miniaturized sensing devices by decorating the pore surface with recognition elements for the detection of biomolecules, ${ }^{24-33}$ anions $^{30,33-39}$ and metal cations. ${ }^{16,40-47}$ Among the various metal cations, alkali metal ions are involved in a variety of essential biological processes. Jiang and co-workers have recognized potassium cation $\left(\mathrm{K}^{+}\right)$with DNA-modified nanopores. ${ }^{47}$ The crown ether functionalized nanopores have the ability to bind specifically to potassium and sodium cations $\left(\mathrm{Na}^{+}\right)$, leading to significant changes in the electronic readout of the pore. ${ }^{43,44}$ 
We have recently demonstrated the detection of cesium cation $\left(\mathrm{Cs}^{+}\right)$by using calixcrown ether functionalized nanopores. ${ }^{46}$ However, the design and development of a nanofluidic device which specifically recognize lithium cation $\left(\mathrm{Li}^{+}\right)$has not been explored.

Lithium is the lightest and less abundant alkali metal. It is the 25th most abundant element in the Earth's crust. Recently, much attention has been paid towards the recognition and extraction of lithium because of its extensive use in pharmaceuticals, heat-resistant ceramics, lubricants, energy technology, and nuclear power plants. ${ }^{48,49}$ Regarding the biomedical application, lithium compounds are successfully used for the treatment of bipolar disorder and may reduce the risk of suicide attempt in patients. ${ }^{50}$ On the other hand, excessive ingestion of lithium can adversely affect the kidneys and nervous system. ${ }^{51}$ Because of the high use of rechargeable lithium ion batteries, especially in portable biomedical devices and mobile phones, the leakage of lithium to environment and its adverse effect cannot be neglected. Hence, techniques and methods are being developed for lithium recognition. ${ }^{52-55}$ However, the coexistence of lithium with other alkali cations in liquid solutions makes it difficult to selectively recognize it.

We design and miniaturize a functional nanofluidic device exhibiting selectivity to lithium ion in the presence of other alkali cations. To this end, single conical nanopores in polymers membranes are fabricated and chemically modified with lithium-selective receptor moieties, the aminoethyl-benzo-12-crown-4 (BC12C4$\mathrm{NH}_{2}$ ). The modified pore is evaluated with different alkali metal chloride solutions and exhibits current rectification only for the case of the lithium chloride solution. Because B12C4 moieties on the pore surface generate $\mathrm{B} 12 \mathrm{C} 4-\mathrm{Li}^{+}$complexes, the pore surface charge changes from neutral to positive, becoming anion selective as 
revealed from the inversion observed in the ion current rectification. The experimental results show that the nanofluidic device can recognise lithium ion at lower concentrations, even in the presence of other metal cations in the electrolyte solution.

\section{Materials and methods}

\subsection{Materials}

Polyethylene terephthalate (PET, Hostaphan RN 12, Hoechst, $12 \mu \mathrm{m}$ thick) foils, $N$-(3-dimethylaminopropyl)- $N$ '-ethylcarbodiimide· hydrochloride

$(\mathrm{EDC} \cdot \mathrm{HCl})$ pentafluorophenol (PFP), dopamine hydrochloride (DA), triethylamine, di-tert-butyl dicarbonate $\left.\left(\mathrm{Boc}_{2}\right) \mathrm{O}\right)$, triethylene glycol, $p$-toluenesulfonyl chloride, potassium $t$ butoxide ( $t$-BuOK), potassium carbonate $\left(\mathrm{K}_{2} \mathrm{CO}_{3}\right)$, trifluoroacetic acid (TFA), lithium chloride ( $\mathrm{LiCl})$, sodium chloride, $(\mathrm{NaCl})$, potassium chloride $(\mathrm{KCl})$, rubidium chloride $(\mathrm{RbCl})$ and cesium chloride $(\mathrm{CsCl})$ were used in this study. All the chemical and solvent were purchased from Sigma-Aldrich, Taufkirchen, Germany, and used without further purification.

${ }^{1} \mathrm{H}$ and ${ }^{13} \mathrm{C}$ NMR spectra were recorded at 500 and $125 \mathrm{MHz}$ in $\mathrm{CDCl}_{3}$, respectively. High-resolution mass spectra were measured using a Finnigan MAT90 mass spectrometer. Analytical TLC (silica gel, 60F-54, Merck) and spots were visualized under UV light and/or phosphomolybdic acid-ethanol. Flash column chromatography was performed with silica gel 60 (70-230 mesh, Merck) and basic aluminum oxide (activated, basic, 150 mesh, $58 \AA$, Aldrich).

\subsection{Fabrication of single asymmetric nanopores}

Single conical nanopores in PET membranes were fabricated through asymmetric chemical etching of latent ion tracks. ${ }^{15}$ For this purpose, PET foils were first irradiated 
with single swift heavy ions $(\mathrm{Au})$ of kinetic energy $11.4 \mathrm{MeV} /$ nucleon at the linear accelerator UNILAC (GSI Helmholtz Centre for Heavy Ion Research, Darmstadt, Germany). Then, the latent ion tracks in polymer membranes were sensitized with soft UV light. The chemical track-etching process was performed in a custom-made conductivity cell having three chambers. The chemical asymmetric track-etching process can be found elsewhere ${ }^{15}$. Briefly, an etching solution $(9 \mathrm{M} \mathrm{NaOH})$ was filled in the middle compartment and the stopping solution (1 $\mathrm{M} \mathrm{KCl}+1 \mathrm{M} \mathrm{HCOOH})$ was filled on the side chambers. The etching process was carried out at room temperature and monitored by applying a potential of $-1 \mathrm{~V}$ across the membrane. After the breakthrough, the etching process was stopped when the current reached a certain defined value. Then, the etched membrane was washed with stopping solution, followed by deionized water. The etched sample was dipped in deionized water overnight in order to remove the residual salts. The chemical etching process resulted in the generation of carboxylic groups $(\mathrm{COOH})$ on the inner pore walls due to the hydrolysis of ester bonds in the back-bone of polymer chains.

\subsection{Synthesis of aminoethyl-benzo-12-crown-4 (B12C4- $\left.\mathrm{NH}_{2}\right)$}

Figure 1 depicts the preparation of the different crown ether derivatives involved in the synthesis of aminoethyl-benzo-12-crown-4 (4) following previously reported reaction procedures with slight modifications. ${ }^{56-58}$ Details of the synthesis are given in the Electronic Supplementary Information (ESI) file.

We have synthesised aminoethyl-benzo-12-crown-4 (B12C4- $\left.\mathrm{NH}_{2}\right)$ to modulate the nanopore surface chemistry and transport properties in response to lithium cation. The reaction scheme for the synthesis of $\mathrm{B} 12 \mathrm{C} 4-\mathrm{NH}_{2}$ is shown in Figure 1. The first step was the protection of amine group of dopamine hydrochloride (DA). ${ }^{56}$ For this purpose, $N$-tert-butoxycarbonyl-3,4-dihydroxyphenylethylamine (1) was prepared by 
treating commercially available DA with di-tert-butyl dicarbonate in the presence of triethylamine. The second step was the synthesis of triethylene glycol ditosylate (2) by reacting triethylene glycol and p-toluenesulfonyl chloride in sodium hydroxide and THF mixture. ${ }^{57}$ Protected crown ether $\mathbf{3}$ was obtained by refluxing compound (1) and compound (2) with potassium carbonate in dried acetonitrile. ${ }^{58}$ Finally, the deprotection of $\mathrm{N}$-boc group was carried out using trifluoroacetice acid to afford B12C4- $\mathrm{NH}_{2}$ (4). The chemical structures of synthetic crown ether derivatives were characterized through 1H NMR, 13C NMR and HRMS-FAB techniques.

\subsection{Chemical functionalization of nanopore surface}

The carboxylic acid groups on the pore surface were first activated by exposing the track-etched single-pore membrane to an ethanol solution containing EDC (100 mM) and PFP (200 mM) at room temperature for $1 \mathrm{~h}$. After washing with ethanol several times, the activated pore was treated with B12C4- $\mathrm{NH}_{2}(35 \mathrm{mM})$ solution for $24 \mathrm{~h}$. During this reaction period, amine-reactive PFP-esters were covalently coupled with the amine group of the $\mathrm{B} 12 \mathrm{C} 4-\mathrm{NH}_{2}$. Subsequently, the modified pore was washed thoroughly with ethanol followed by careful rinsing with deionized water.

\subsection{Current-voltage measurements}

The unmodified and modified pores were characterized by measuring the currentvoltage $(I-V)$ curves before and after functionalization. The electrolyte solutions were prepared in $10 \mathrm{mM}$ tris-buffer. The measurement of $I-V$ curve was performed using a picoammeter/voltage source (Keithley 6487, Keithley Instruments, Cleveland, Ohio, USA) and the LabVIEW 6.1 software (National Instruments). For this purpose, the single-pore as-prepared membrane was fixed between the two compartments of the conductivity cell. An aqueous electrolyte was filled in both halves of the cell. The 
electrodes consisting of a Ag wire coated with AgCl were inserted into each half-cell solution to establish a transmembrane potential difference (voltage $V$ ) and the ionic current $I$ through the pore was then measured. In the present case, the ground was placed on the big opening side and the electrodes facing the tip side of the conical nanopore. Then a scanning triangle voltage signal was applied from -1 to $+1 \mathrm{~V}$ across the membrane to record the $I-V$ curves.

\subsection{Modeling}

The theoretical $I-V$ curves were calculated using the Poisson and NernstPlanck (PNP) equations

$$
\begin{aligned}
& \nabla^{2} \phi=-\frac{F}{\varepsilon} \sum_{i} z_{i} c_{i}, \\
& \nabla \cdot \vec{J} i=-\nabla \cdot\left[D_{i}\left(\nabla c_{i}+\frac{F}{R T} z_{i} c_{i} \nabla \emptyset\right)\right]
\end{aligned}
$$

where $R$ is the gas constant, $F$ is the Faraday constant, and $T$ is the absolute temperature. In these equations, $\phi$ is the electric potential and $\varepsilon$ is the electrical permittivity of the solution. $\vec{J}_{\mathrm{i}}, D_{\mathrm{i}}, z_{\mathrm{i}}, c_{\mathrm{i}}$, and are, respectively, the flux, the diffusion coefficient, the charge number, and the local concentration of the ionic species $i$. The boundary condition for the electric potential is the Gauss law

$$
\left.\frac{1}{r} \frac{\partial \phi}{\partial \theta}\right|_{\substack{\text { purfe } \\ \text { surface }}}=\frac{\sigma}{\varepsilon},
$$

where $r$ and $\theta$ are spherical coordinates with the origin in the cone apex and $\sigma$ is the surface concentration of fixed charges. The boundary conditions for the ionic concentrations are based on the Donnan equilibrium conditions for the external and pore solution concentrations. Solving Equations (1)-(2) at a given applied voltage $V$, allows for the calculation of the ionic fluxes, the axial profiles of electric potential and ionic concentrations, and the electric current 


$$
I=\sum_{i} z_{i} F \pi a^{2} J_{i}
$$

through a pore section of radius $a$. Additional equations for the boundary conditions and numerical details can be found in References 59-62.

\section{Results and discussion}

Figure 2A shows the chemical modification of the $\mathrm{COOH}$ groups with amineterminated benzo-12-crown-4 (B12C4- $\left.\mathrm{NH}_{2}\right)$ molecules through carbodiimide coupling chemistry. The crown ethers are known to selectively bind a metal cation, depending on their cavity size (Figure 2B). The lithium cation is captured by the 12crown-4 moieties because the metal cation $\left(\mathrm{Li}^{+}\right)$diameter $(140 \mathrm{pm})$ is comparable to the cavity size (120 to $150 \mathrm{pm})$ of the macrocycle.

The nanopores are characterized by measuring the asymmetric $I-V$ curves which are sensitive to the pore surface charges. Indeed, these charges interact with the ions passing through the nanopore and then oppositely charged pores show different rectifications. Thus, the pore functionalization can be confirmed by measuring the $I-V$ characteristics before and after modification of the nanopore.

Figures 3A (experiment) and 3B (model) illustrate the characterization of the unmodified (as-prepared) nanopore in symmetric $100 \mathrm{mM} \mathrm{KCl}$ solutions. Assuming infinite dilution values for the diffusion coefficients of the ionic species and a conical geometry for the pore, the only unknown model parameters are the pore tip $(d)$ and base $(D)$ diameters, and the surface concentration of fixed charges, $\sigma$. The pore base diameter determined from the etching time is $D=400 \mathrm{~nm}$. At $\mathrm{pH}=3.5$, the carboxylic acid groups attached on the pore walls are protonated ( $\sigma=0)$, leading to a quasi-linear $I-V$ curve. Fitting the theoretical model to the experimental data gives then the pore 
tip diameter $d=10 \mathrm{~nm}$. At close to neutral $\mathrm{pH}$ values, the pore shows rectification because of the asymmetric distribution of the fixed charges and the electric potential along the axis. High currents are obtained at positive voltages and low currents at negative voltages, as shown in Figure $3 \mathrm{~A} .^{59-64}$ This fact leads to the preferential transport of cations from the tip to the base opening of the conical nanopore. The only unknown model parameter $\sigma$ is then calculated by fitting the theoretical model to the experimental data of Figure $3 \mathrm{~A}$ at $\mathrm{pH}=6.5$, giving $\sigma=-0.25 e / \mathrm{nm}^{2}$, where $e$ is the elementary charge. In this estimation, we assume that the $\mathrm{COO}^{-}$groups are homogeneously distributed on the pore walls.

Figure $3 C$ shows the $I-V$ curves of the as-prepared single conical nanopore measured in $100 \mathrm{mM}$ alkali salt solutions. On exposure to various alkali cations, the unmodified nanopore exhibits similar current rectifications and the currents measured for different cations can be described using the values of the diffusion coefficients of the different cations at infinite dilution. Figure 3D shows the theoretical results obtained with the same model parameters as in Figure 3B. The good agreement between theory and experiment supports the assumptions concerning the conical pore geometry and the fixed charge distribution.

We functionalize the carboxylic acid groups on the pore surface with crown ether (host) moieties to selectively capture the lithium cation (guest). For this purpose B12C4- $\mathrm{NH}_{2}$ is immobilized on the pore surface as described in Figure 2A. The modified pore $I-V$ characteristics of Figure 3E show that derivatization of carboxylic acid groups with uncharged B12C4 moieties results in the loss of the pore negative charges. This fact leads to a significant decrease of the pore rectification for the case of $\mathrm{Na}^{+}, \mathrm{K}^{+}, \mathrm{Rb}^{+}$and $\mathrm{Cs}^{+}$, suggesting no complexation of these cations with the B12C4 moieties. In this case, the metal cation diameters do not match the cavity size of the 
immobilized crown ether groups. On the contrary, Figure 3E shows that upon exposure to $\mathrm{LiCl}$ solution, the modified pore exhibits a reversal in the current rectification which is attributed to the switching of the pore charge from negative to positive due the specific binding of $\mathrm{Li}^{+}$cation with the crown ether moieties. The rectification ratios for the alkali cations on the left ordinate axis are obtained by dividing the average value of the negative current to the positive currents (red columns). In the case of the right ordinate axis, we consider the ratio of the positive to the negative currents (blue columns), as shown in the inset of Figure 3E. The clear difference observed between the rectification ratio for lithium and the other cations further confirm the formation of positively charged $\mathrm{B} 12 \mathrm{C} 4-\mathrm{Li}^{+}$complexes on the pore surface for the electrolyte solution having $\mathrm{Li}^{+}$cations.

Because of the positively charged $\mathrm{B} 12 \mathrm{C} 4-\mathrm{Li}^{+}$chelates, the nanopore preferentially attracts the anions $\left(\mathrm{Cl}^{-}\right)$and excludes the cations $\left(\mathrm{Li}^{+}\right)$, thus reversing the current rectifcation of $I-V$ curve $^{17}$ (Figure $3 E$ ). Note the different rectification ratios shown in the inset of Figure 3E. Figure 3F shows the theoretical curves obtained using the model parameters given in the figure. In order to reproduce the measured currents, the pore diameters must be decreased by $5 \mathrm{~nm}$ because of the functionalization of the functional crown ether moieties on the surface. The curves corresponding to $\mathrm{Na}^{+}, \mathrm{K}^{+}$, $\mathrm{Rb}^{+}$and $\mathrm{Cs}^{+}$are calculated by assuming $\sigma=-0.02 \mathrm{e} / \mathrm{nm}^{2}$, while the curve for $\mathrm{Li}^{+}$is reproduced using $\sigma=+0.22 \mathrm{e} / \mathrm{nm}^{2}$ in the model. The fact that the pore surface charge remains slightly negative for $\mathrm{Na}^{+}, \mathrm{K}^{+}, \mathrm{Rb}^{+}$and $\mathrm{Cs}^{+}$after chemical modification. This suggests that the immobilization of crown ether moieties of Figure $2 \mathrm{~A}$ is not $100 \%$ efficient, leaving unmodified $\mathrm{COO}^{-}$groups on the pore surface. These carboxylate groups are responsible for the partial negative pore surface change after chemical reaction as evidenced from the $I-V$ behaviour of the pore shown in Figure 3E. 
Figures $4 \mathrm{~A}$ and $4 \mathrm{~B}$ show the lithium-crown ether complexation and the $I-V$ characteristics of the modifed pore at different lithium concentrations. The background electrolyte (10 $\mathrm{mM}$ tris buffer, $\mathrm{pH}$ 6.5) gives an essentially nonconducting pore with very low currents $(\sim 4 \mathrm{pA})$.

The experiments in Figure 4B show that when the modified pore is exposed to solutions of $1 \mu \mathrm{M}$ and $10 \mu \mathrm{M} \mathrm{Li}{ }^{+}$concentrations, the modified pore starts rectification with an increase of ion current at $-1 \mathrm{~V}$ from $4 \mathrm{pA}$ to $20 \mathrm{pA}$ and 60 $\mathrm{pA}$, respectively, because of the formation of positively charged $\mathrm{B} 12 \mathrm{C} 4-\mathrm{Li}^{+}$ complex (Figure 4A) on the pore surface. Further increasing of the $\mathrm{Li}^{+}$ion concentration from $10 \mu \mathrm{M}$ to $100 \mathrm{mM}$, gives gradual increases of the rectified current from $60 \mathrm{pA}$ to $700 \mathrm{pA}$ measured at $-1 \mathrm{~V}$. On te contrary, only small changes in the current at $+1 \mathrm{~V}$ occur when exposing the pore to different $\mathrm{Li}^{+}$ion concentrations. These facts clearly show that B12C4- $\mathrm{Li}^{+}$complexes allow $\mathrm{Li}^{+}$ sensing over a wide range of concentrations. The theoretical calculations of Figure 4B reproduce well the experimental data at concentrations of $\mathrm{Li}^{+}$higher than that of the tris buffer $(10 \mathrm{mM})$, suggesting that for $\mathrm{Li}^{+}$concentrations lower than 10 $\mathrm{mM}$ most of the current is transported by the buffer electrolyte.

To study the reproducibility of the data, we have modified a second conical nanopore under the same set of experimental conditions. In this case, the characteristic pore parameters are $D=500 \mathrm{~nm}, d=22 \mathrm{~nm}$, and $\sigma=-0.5 e / \mathrm{nm}^{2}$. The experiments of Figure 5A show the small changes obtained in the $I-V$ curves for solutions of $\mathrm{NaCl}, \mathrm{KCl}, \mathrm{RbCl}$ and $\mathrm{CsCl}$ at $100 \mathrm{mM}$ after pore modification. This is not the case of the $\mathrm{LiCl} 100 \mathrm{mM}$ solution, where a significant current rectification is obtained again because of the positively charged B12C4- $\mathrm{Li}^{+}$complex. Figure 5B shows the theoretical curves obtained using the model parameters given in the 
figure, revealing that the immobilization of crown ether groups on $\mathrm{COO}^{-}$is now much more efficient than in the case of the sample of Figures 3 and 4.

We consider now the case of electrolyte mixtures in Figure 5C. By increasing the concentration of $\mathrm{LiCl}$ from zero to $20 \mathrm{mM}$ in the mixture at constant total electrolyte concentration $(100 \mathrm{mM})$, the nanopore starts rectifying the current, suggesting the binding of the $\mathrm{Li}^{+}$ion with the crown ether moieties even in the presence of a high $\mathrm{K}^{+}$concentration $(80 \mathrm{mM})$. Increasing further the fraction of lithium over potassium gives relatively low rectification changes indicating the saturation of positive charges (B12C4- $\mathrm{Li}^{+}$) at $40 \mathrm{mM} \mathrm{LiCl}$ approximately.

We have also examined the reversibility of lithium ion recognition. Potassium ion does not fit to the cavity size of B12C4 moieties and can then be used as a control electrolyte to check this reversibility. To this end, the modified pore is exposed alternatively to $\mathrm{KCl}$ and $\mathrm{LiCl}$ solutions and the ion currents are measured at $-1 \mathrm{~V}$. Figure 5D shows the results obtained over different cycles of reversible $\mathrm{Li}^{+}$binding and unbinding. The reversible changes observed suggest that it is the surface charge density that dictates the pore properties from a non-conducting state with B12C4 moieties to a conducting state with B12C4- $\mathrm{Li}^{+}$chelates.

Finally, we have considered the modified pore under acidic conditions ( $\mathrm{pH} 3.5$ ). The $I-V$ curves of Figure 6 were obtained using a third functionalized pore sample. The modified pore shows anion selectivity to all alkali metal cation solutions, suggesting the loss of specific binding to lithium due to the protonation of crown ether moieties. $^{65}$

\section{Conclusions}


In summary, we have demonstrated the miniaturization of a nanofluidic device based on a single conical nanopore for lithium ion specific recognition. On exposure to $\mathrm{LiCl}$ solutions, host-guest ion recognition occurs in the confined geometry, leading to the switching of the nanopore charges from neutral to positive because of the $\mathrm{Li}^{+}-$ crown ether complexes formed on the surface. This process leads to significant changes in the pore rectification characteristics, which depend on the asymmetrical distribution of positively charged groups along the pore axis. On the contrary, other alkali metal cations do not give significant changes because they are unable to bind with the immobilized crown ether groups. The experimental data are well described by a theoretical model based on the Poisson and Nernst-Planck equations and show that the electrical characteristics of the single-pore membrane change significantly over a wide range of lithium ion concentrations in the solution. Moreover, the nanodevice can detect lithium ions even in the presence of other metal cations in mixtures of electrolyte solutions. In summary, we believe that this study can contribute significantly to the design and development of nanostructured materials for the recognition, separation, and extraction of lithium ions.

\section{Supporting Information}

The Supporting Information is available free of charge on the ACS Publications website at DOI:

Supporting information contains scheme and detailed synthesis of aminoethyl-benzo12-crown-4 (B12C4- $\left.\mathrm{NH}_{2}\right)$. 


\section{Acknowledgements}

M.A., S.N. and W.E. acknowledge the funding from the Hessen State Ministry of Higher Education, Research and the Arts, Germany, under the LOEWE project iNAPO. P.R. and S.M. acknowledge financial support by the Spanish Ministry of Economic Affairs and Competitiveness (MAT2015-65011-P), and FEDER. I.A. and C.M.N. acknowledge financial support through the Helmholtz programme BioInterfaces in Technology and Medicine. The authors are thankful to Prof. Christina Trautmann from GSI (Department of Material Research) for support with the heavy ion irradiation experiments. 


\section{References}

(1) Hille, B.: Ionic channels of excitable membranes; 3rd ed.; Sinauer Associates Inc.: Sunderland, MA, 2001.

(2) Favre, I.; Moczydlowski, E.; Schild, L. On the structural basis for ionic selectivity among $\mathrm{Na}+, \mathrm{K}+$, and $\mathrm{Ca} 2+$ in the voltage-gated sodium channel. Biophys. J. 1996, 71, 3110-3125.

(3) Payandeh, J.; Scheuer, T.; Zheng, N.; Catterall, W. A. The crystal structure of a voltage-gated sodium channel. Nature 2011, 475, 353.

(4) Agre, P. Aquaporin Water Channels (Nobel Lecture). Angew. Chem. Int. Ed. 2004, 43, 4278-4290.

(5) Doupnik, C. A.; Davidson, N.; Lester, H. A. The inward rectifier potassium channel family. Curr. Opin. Neurobiol. 1995, 5, 268-277.

(6) MacKinnon, R. Potassium Channels and the Atomic Basis of Selective Ion Conduction (Nobel Lecture). Angew. Chem. Int. Ed. 2004, 43, 4265-4277.

(7) Biró, I.; Pezeshki, S.; Weingart, H.; Winterhalter, M.; Kleinekathöfer, U. Comparing the Temperature-Dependent Conductance of the Two Structurally Similar E. coli Porins OmpC and OmpF. Biophys. J. 2010, 98, 1830-1839.

(8) Jung, Y.; Bayley, H.; Movileanu, L. Temperature-Responsive Protein Pores. J. Am. Chem. Soc. 2006, 128, 15332-15340.

(9) Bayley, H.; Cremer, P. S. Stochastic sensors inspired by biology. Nature 2001, 413, 226-230.

(10) Healy, K. Nanopore-based single-molecule DNA analysis. Nanomedicine 2007, 2, 459-481.

(11) Howorka, S.; Siwy, Z. Nanopore analytics: sensing of single molecules. Chem. Soc. Rev. 2009, 38, 2360-2384.

(12) Dekker, C. Solid-state nanopores. Nat. Nanotechnol. 2007, 2, 209-215.

(13) Hou, X.; Guo, W.; Jiang, L. Biomimetic smart nanopores and nanochannels. Chem. Soc. Rev. 2011, 40, 2385-2401.

(14) Siwy, Z. S.; Howorka, S. Engineered voltage-responsive nanopores. Chem. Soc. Rev. 2010, 39, 1115-1132.

(15) Apel, P. Y.; Korchev, Y. E.; Siwy, Z.; Spohr, R.; Yoshida, M. DiodeLike Single-Ion Track Membrane Prepared by Electro-Stopping. Nucl. Instrum. Methods Phys. Res., Sect. B 2001, 184, 337-346.

(16) Ali, M.; Nasir, S.; Ramirez, P.; Cervera, J.; Mafe, S.; Ensinger, W. Calcium Binding and Ionic Conduction in Single Conical Nanopores with Polyacid Chains: Model and Experiments. ACS Nano 2012, 6, 9247-9257.

(17) Ali, M.; Ramirez, P.; Nguyen, H. Q.; Nasir, S.; Cervera, J.; Mafe, S.; Ensinger, W. Single Cigar-Shaped Nanopores Functionalized with Amphoteric Amino Acid Chains: Experimental and Theoretical Characterization. ACS Nano 2012, 6, 3631-3640.

(18) Gyurcsanyi, R. E. Chemically-modified nanopores for sensing. Trends Anal. Chem. 2008, 27, 627-639.

(19) Lepoitevin, M.; Nguyen, G.; Bechelany, M.; Balanzat, E.; Janot, J.-M.; Balme, S. Combining a sensor and a pH-gated nanopore based on an avidin-biotin system. Chem. Commun. 2015, 51, 5994-5997.

(20) Wen, L.; Tian, Y.; Ma, J.; Zhai, J.; Jiang, L. Construction of biomimetic smart nanochannels with polymer membranes and application in energy conversion systems. Phys. Chem. Chem. Phys. 2012, 14, 4027-4042. 
(21) Zhang, H.; Hou, X.; Zeng, L.; Yang, F.; Li, L.; Yan, D.; Tian, Y.; Jiang, L. Bioinspired Artificial Single Ion Pump. J. Am. Chem. Soc. 2013, 135, 16102-16110.

(22) Zhang, H.; Tian, Y.; Jiang, L. From symmetric to asymmetric design of bio-inspired smart single nanochannels. Chem. Commun. 2013, 49, 10048-10063.

(23) Hou, X.; Zhang, H. C.; Jiang, L. Building Bio-Inspired Artificial Functional Nanochannels: From Symmetric to Asymmetric Modification. Angew. Chem. Int. Ed. 2012, 51, 5296-5307.

(24) Ali, M.; Nasir, S.; Ensinger, W. Bioconjugation-induced ionic current rectification in aptamer-modified single cylindrical nanopores. Chem. Commun. 2015, 51, 3454-3457.

(25) Ali, M.; Nasir, S.; Ensinger, W. Stereoselective detection of amino acids with protein-modified single asymmetric nanopores. Electrochim Acta 2016, 215, 231-237.

(26) Ali, M.; Nasir, S.; Ramirez, P.; Cervera, J.; Mafe, S.; Ensinger, W. Carbohydrate-Mediated Biomolecular Recognition and Gating of Synthetic Ion Channels. J. Phys. Chem. C 2013, 117, 18234-18242.

(27) Ali, M.; Neumann, R.; Ensinger, W. Sequence-Specific Recognition of DNA Oligomer Using Peptide Nucleic Acid (PNA)-Modified Synthetic Ion Channels: PNA/DNA Hybridization in Nanoconfined Environment. ACS Nano 2010, 4, 72677274.

(28) Han, C.; Hou, X.; Zhang, H.; Guo, W.; Li, H.; Jiang, L. Enantioselective Recognition in Biomimetic Single Artificial Nanochannels. J. Am. Chem. Soc. 2011, 133, 7644-7647.

(29) Siwy, Z.; Trofin, L.; Kohli, P.; Baker, L. A.; Trautmann, C.; Martin, C. R. Protein biosensors based on biofunctionalized conical gold nanotubes. J. Am. Chem. Soc. 2005, 127, 5000-5001.

(30) Song, M.; Sun, Z.; Han, C.; Tian, D.; Li, H.; Jiang, L. Design and Fabrication of a Biomimetic Nanochannel for Highly Sensitive Arginine Response in Serum Samples. Chem. Eur. J. 2014, 20, 7987-7993.

(31) Vlassiouk, I.; Kozel, T. R.; Siwy, Z. S. Biosensing with Nanofluidic Diodes. J. Am. Chem. Soc. 2009, 131, 8211-8220.

(32) Xie, G.; Tian, W.; Wen, L.; Xiao, K.; Zhang, Z.; Liu, Q.; Hou, G.; Li, P.; Tian, Y.; Jiang, L. Chiral recognition of l-tryptophan with beta-cyclodextrinmodified biomimetic single nanochannel. Chem. Commun. 2015, 51, 3135-3138.

(33) Zhang, F.; Sun, Y.; Tian, D.; Li, H. Chiral Selective Transport of Proteins by Cysteine-Enantiomer-Modified Nanopores. Angew. Chem. Int. Ed. 2017, 56, 7186-7190.

(34) Liu, Q.; Wen, L.; Xiao, K.; Lu, H.; Zhang, Z.; Xie, G.; Kong, X.-Y.; Bo, Z.; Jiang, L. A Biomimetic Voltage-Gated Chloride Nanochannel. Adv. Mater. 2016, 28, 3181-3186.

(35) Liu, Q.; Xiao, K.; Wen, L.; Dong, Y.; Xie, G.; Zhang, Z.; Bo, Z.; Jiang, L. A Fluoride-Driven Ionic Gate Based on a 4-Aminophenylboronic AcidFunctionalized Asymmetric Single Nanochannel. ACS Nano 2014, 8, 12292-12299.

(36) Nie, G.; Sun, Y.; Zhang, F.; Song, M.; Tian, D.; Jiang, L.; Li, H. Fluoride responsive single nanochannel: click fabrication and highly selective sensing in aqueous solution. Chem. Sci. 2015, 6, 5859-5865.

(37) Xie, G.; Xiao, K.; Zhang, Z.; Kong, X.-Y.; Liu, Q.; Li, P.; Wen, L.; Jiang, L. A Bioinspired Switchable and Tunable Carbonate-Activated Nanofluidic 
Diode Based on a Single Nanochannel. Angew. Chem. Int. Ed. 2015, 54, 1366413668.

(38) Zhang, F.; Ma, J.; Sun, Y.; Boussouar, I.; Tian, D.; Li, H.; Jiang, L. Fabrication of a mercaptoacetic acid pillar[5]arene assembled nanochannel: a biomimetic gate for mercury poisoning. Chem. Sci. 2016, 7, 3227-3233.

(39) Wang, R.; Sun, Y.; Zhang, F.; Song, M.; Tian, D.; Li, H. TemperatureSensitive Artificial Channels through Pillar[5]arene-based Host-Guest Interactions. Angew. Chem. Int. Ed. 2017, 56, 5294-5298.

(40) Ali, M.; Ahmed, I.; Ramirez, P.; Nasir, S.; Niemeyer, C. M.; Mafe, S.; Ensinger, W. Label-Free Pyrophosphate Recognition with Functionalized Asymmetric Nanopores. Small 2016, 12, 2014-2021.

(41) Ali, M.; Nasir, S.; Nguyen, Q. H.; Sahoo, J. K.; Tahir, M. N.; Tremel, W.; Ensinger, W. Metal Ion Affinity-based Biomolecular Recognition and Conjugation inside Synthetic Polymer Nanopores Modified with Iron-Terpyridine Complexes. J. Am. Chem. Soc. 2011, 133, 17307-17314.

(42) Han, C.; Su, H.; Sun, Z.; Wen, L.; Tian, D.; Xu, K.; Hu, J.; Wang, A.; Li, H.; Jiang, L. Biomimetic Ion Nanochannels as a Highly Selective Sequential Sensor for Zinc Ions Followed by Phosphate Anions. Chem. Eur. J. 2013, 19, 93889395.

(43) Liu, Q.; Xiao, K.; Wen, L.; Lu, H.; Liu, Y.; Kong, X.-Y.; Xie, G.; Zhang, Z.; Bo, Z.; Jiang, L. Engineered Ionic Gates for Ion Conduction Based on Sodium and Potassium Activated Nanochannels. J. Am. Chem. Soc. 2015, 137, 1197611983.

(44) Perez-Mitta, G.; Albesa, A. G.; Knoll, W.; Trautmann, C.; ToimilMolares, M. E.; Azzaroni, O. Host-guest supramolecular chemistry in solid-state nanopores: potassium-driven modulation of ionic transport in nanofluidic diodes. Nanoscale 2015, 7, 15594-15598.

(45) Tian, Y.; Hou, X.; Wen, L. P.; Guo, W.; Song, Y. L.; Sun, H. Z.; Wang, Y. G.; Jiang, L.; Zhu, D. B. A biomimetic zinc activated ion channel. Chem. Commun. 2010, 46, 1682-1684.

(46) Ali, M.; Ahmed, I.; Ramirez, P.; Nasir, S.; Cervera, J.; Mafe, S.; Niemeyer, C. M.; Ensinger, W. Cesium-Induced Ionic Conduction through a Single Nanofluidic Pore Modified with Calixcrown Moieties. Langmuir 2017, 33, 91709177.

(47) Hou, X.; Guo, W.; Xia, F.; Nie, F. Q.; Dong, H.; Tian, Y.; Wen, L. P.; Wang, L.; Cao, L. X.; Yang, Y.; Xue, J. M.; Song, Y. L.; Wang, Y. G.; Liu, D. S.; Jiang, L. A Biomimetic Potassium Responsive Nanochannel: G-Quadruplex DNA Conformational Switching in a Synthetic Nanopore. J. Am. Chem. Soc. 2009, 131, 7800-7805.

(48) Aral, H.; Vecchio-Sadus, A. Toxicity of lithium to humans and the environment-A literature review. Ecotoxicol. Environ. Saf. 2008, 70, 349-356.

(49) Hartley, J. N.; Gore, B. F.; Young, J. R.: Potential Lithium Requirments for Fusion Power Plants A2 - PENNER, S.S. In Lithium Needs and Resources; Pergamon, 1978; pp 337-346.

(50) Baldessarini, R. J.; Tondo, L.; Davis, P.; Pompili, M.; Goodwin, F. K.; Hennen, J. Decreased risk of suicides and attempts during long-term lithium treatment: a meta-analytic review. Bipolar Disord. 2006, 8, 625-639.

(51) King, J. R.; Phillips, J. D.; Judge, R.; Armond, A. D.; Corbett, J. A.; Birch, N. J. Instant lithium monitoring. Psychiatr. Bull. 2018, 15, 138-139. 
(52) Kamenica, M.; Kothur, R.; Willows, A.; Patel, B.; Cragg, P. Lithium Ion Sensors. Sensors 2017, 17, 2430.

(53) Obare, S. O.; Hollowell, R. E.; Murphy, C. J. Sensing Strategy for Lithium Ion Based on Gold Nanoparticles. Langmuir 2002, 18, 10407-10410.

(54) Luo, Y.; Marets, N.; Kato, T. Selective lithium ion recognition in selfassembled columnar liquid crystals based on a lithium receptor. Chem. Sci. 2018, DOI: 10.1039/C1037SC03652C.

(55) Kimura, K.; Oishi, H.; Miura, T.; Shono, T. Lithium ion selective electrodes based on crown ethers for serum lithium assay. Anal. Chem. 1987, 59, 2331-2334.

(56) Maerten, C.; Garnier, T.; Lupattelli, P.; Chau, N. T. T.; Schaaf, P.; Jierry, L.; Boulmedais, F. Morphogen Electrochemically Triggered Self-Construction of Polymeric Films Based on Mussel-Inspired Chemistry. Langmuir 2015, 31, 1338513393.

(57) Balamurugan, A.; Reddy, M. L. P.; Jayakannan, M. [small pi]Conjugated polymer-Eu3+ complexes: versatile luminescent molecular probes for temperature sensing. J. Mater. Chem. A 2013, 1, 2256-2266.

(58) Ghidini, E.; Ugozzoli, F.; Ungaro, R.; Harkema, S.; Abu El-Fadl, A.; Reinhoudt, D. N. Complexation of alkali metal cations by conformationally rigid, stereoisomeric calix[4]arene crown ethers: a quantitative evaluation of preorganization. J. Am. Chem. Soc. 1990, 112, 6979-6985.

(59) Cervera, J.; Ramirez, P.; Mafe, S.; Stroeve, P. Asymmetric nanopore rectification for ion pumping, electrical power generation, and information processing applications. Electrochim. Acta 2011, 56, 4504-4511.

(60) Cervera, J.; Schiedt, B.; Neumann, R.; Mafe, S.; Ramirez, P. Ionic Conduction, Rectification, and Selectivity in Single Conical Nanopores. J. Chem. Phys. 2006, 124, 104706.

(61) Cervera, J.; Schiedt, B.; Ramirez, P. A Poisson/Nernst-Planck model for ionic transport through synthetic conical nanopores. Europhys. Lett. 2005, 71, 3541.

(62) Ramirez, P.; Apel, P. Y.; Cervera, J.; Mafe, S. Pore Structure and Function of Synthetic Nanopores with Fixed Charges: Tip Shape and Rectification Properties. Nanotechnology 2008, 19, 315707.

(63) Ramirez, P.; Gomez, V.; Cervera, J.; Schiedt, B.; Mafe, S. Ion transport and selectivity in nanopores with spatially inhomogeneous fixed charge distributions. J. Chem. Phys. 2007, 126, 194703.

(64) Siwy, Z. S. Ion-Current Rectification in Nanopores and Nanotubes with Broken Symmetry. Adv. Funct. Mater. 2006, 16, 735-746.

(65) Luo, X.; Guo, B.; Luo, J.; Deng, F.; Zhang, S.; Luo, S.; Crittenden, J. Recovery of Lithium from Wastewater Using Development of Li Ion-Imprinted Polymers. ACS Sustainable Chem. Eng. 2015, 3, 460-467. 
Figures and Legends

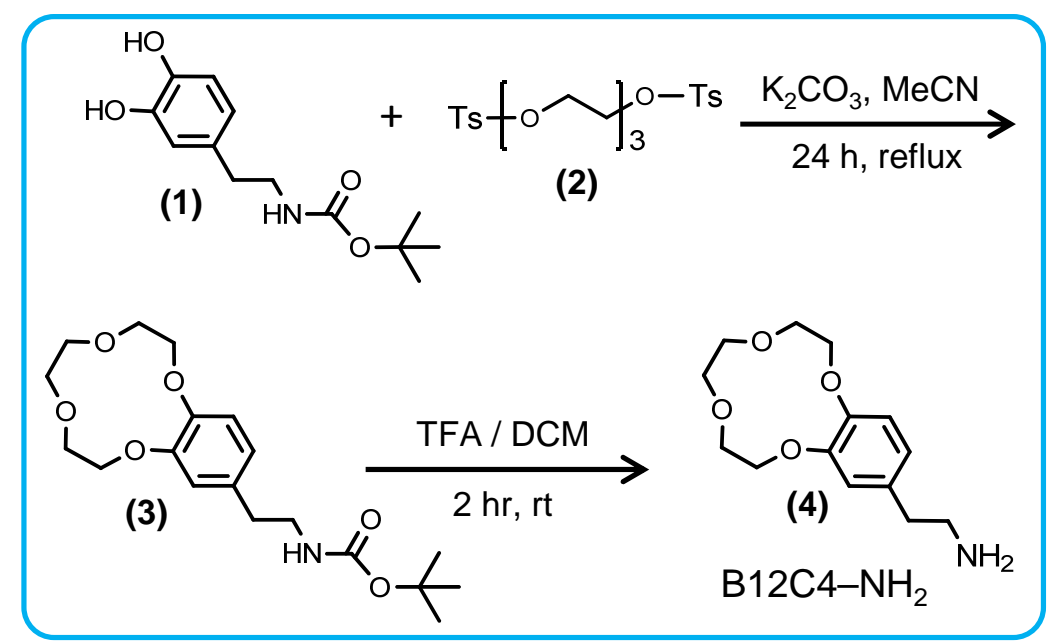

Figure 1. Synthesis of the aminoethyl-benzo-12-crown-4 (B12C4- $\left.\mathrm{NH}_{2}\right)$. 

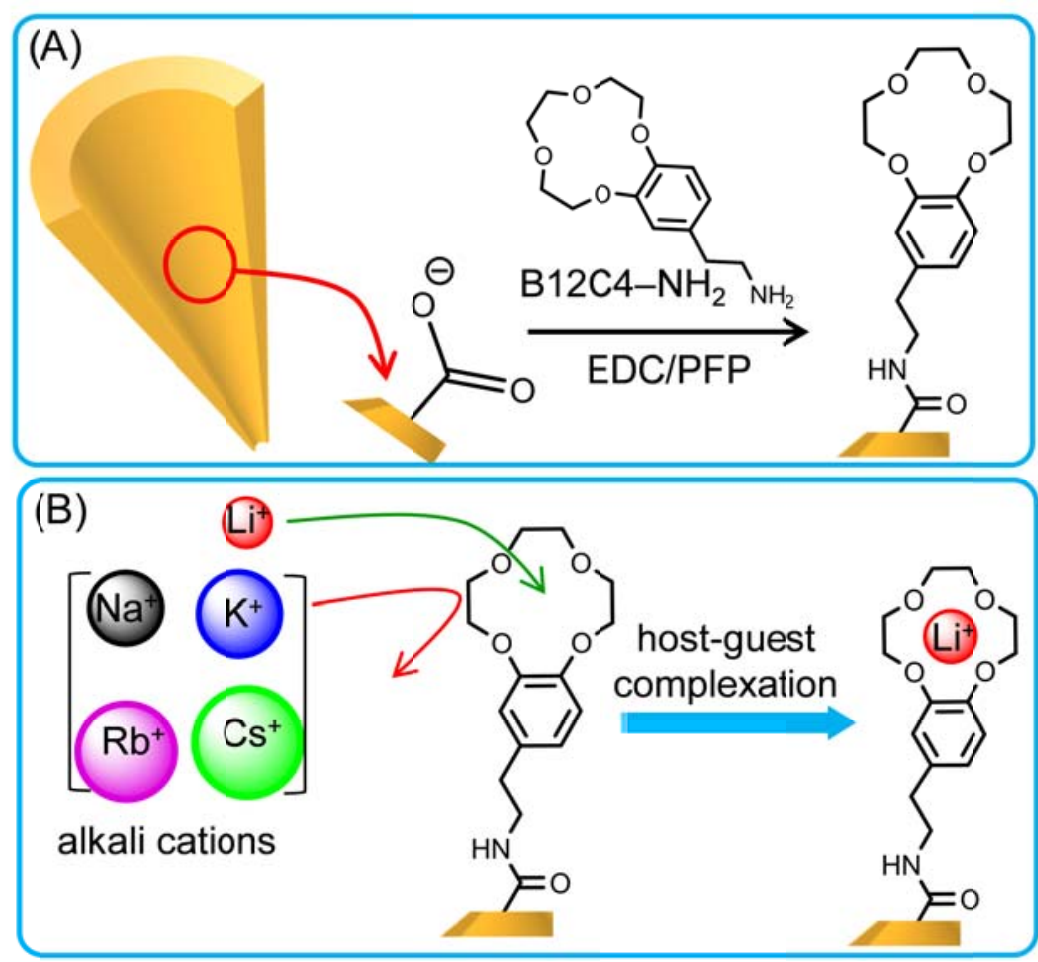

Figure 2. (A) Chemical modification of the carboxylic acid groups on the surface of an asymmetric nanopore with aminoethyl-benzo-12-crown-4 via carbodiimide coupling chemistry. (B) Specific $\mathrm{Li}^{+}$ion complexation with the B12C4 moieties immobilized on the pore surface. 


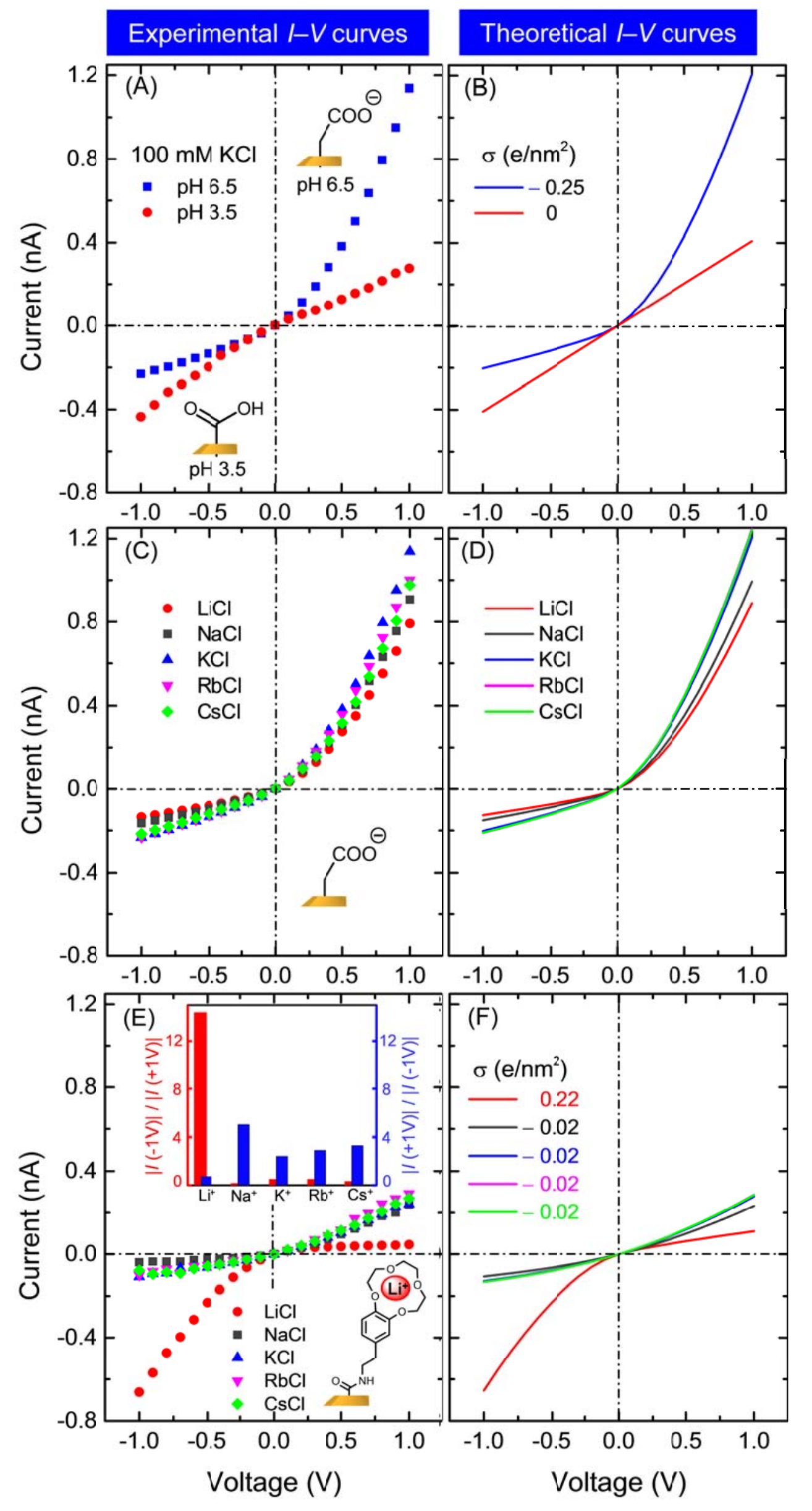


Figure 3. (A) Experimental $I-V$ characteristics of the unmodified pore in $100 \mathrm{mM}$ $\mathrm{KCl}$ solutions at two $\mathrm{pH}$ values. (B) Model calculations corresponding to the experimental data. (C) Experimental $I-V$ characteristics of the unmodified pore exposed to different alkali cation solutions (100 mM, pH 6.5). (D) Model calculations corresponding to the experimental data. (E) Experimental $I-V$ characteristics of the B12C4-modified pore exposed to different alkali cation solutions (100 mM, pH 6.5). The inset shows the rectification ratio versus alkali cation at potential $1 \mathrm{~V}$. (F) Model calculations corresponding to the experimental data. 

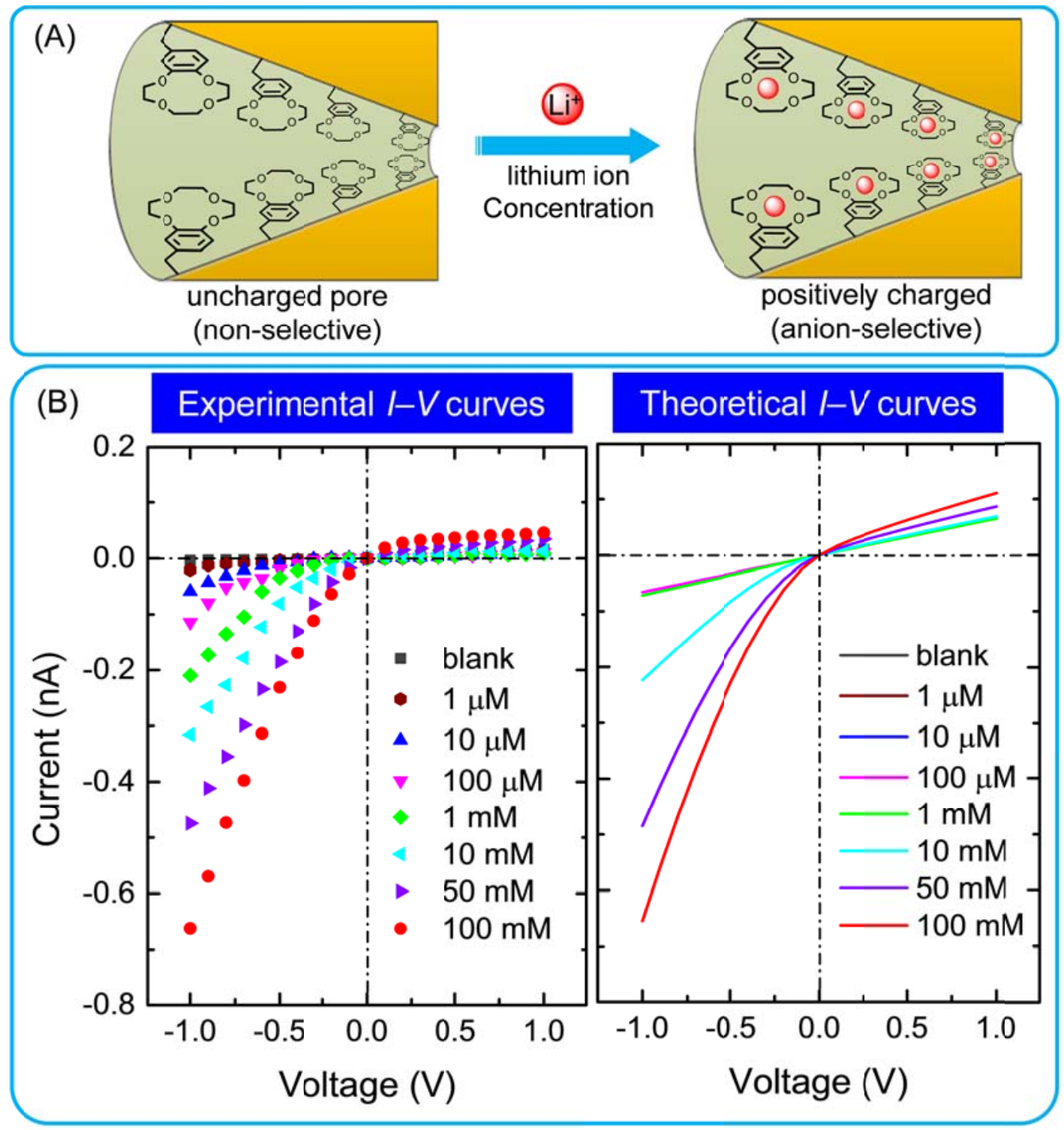

Figure 4. Schematic representation of the lithium-crown ether complexation on the nanopore surface (A). Experimental and theoretical $I-V$ characteristics of the modified pore of Figure 3 exposed to different lithium ion concentrations in the solution (B). 

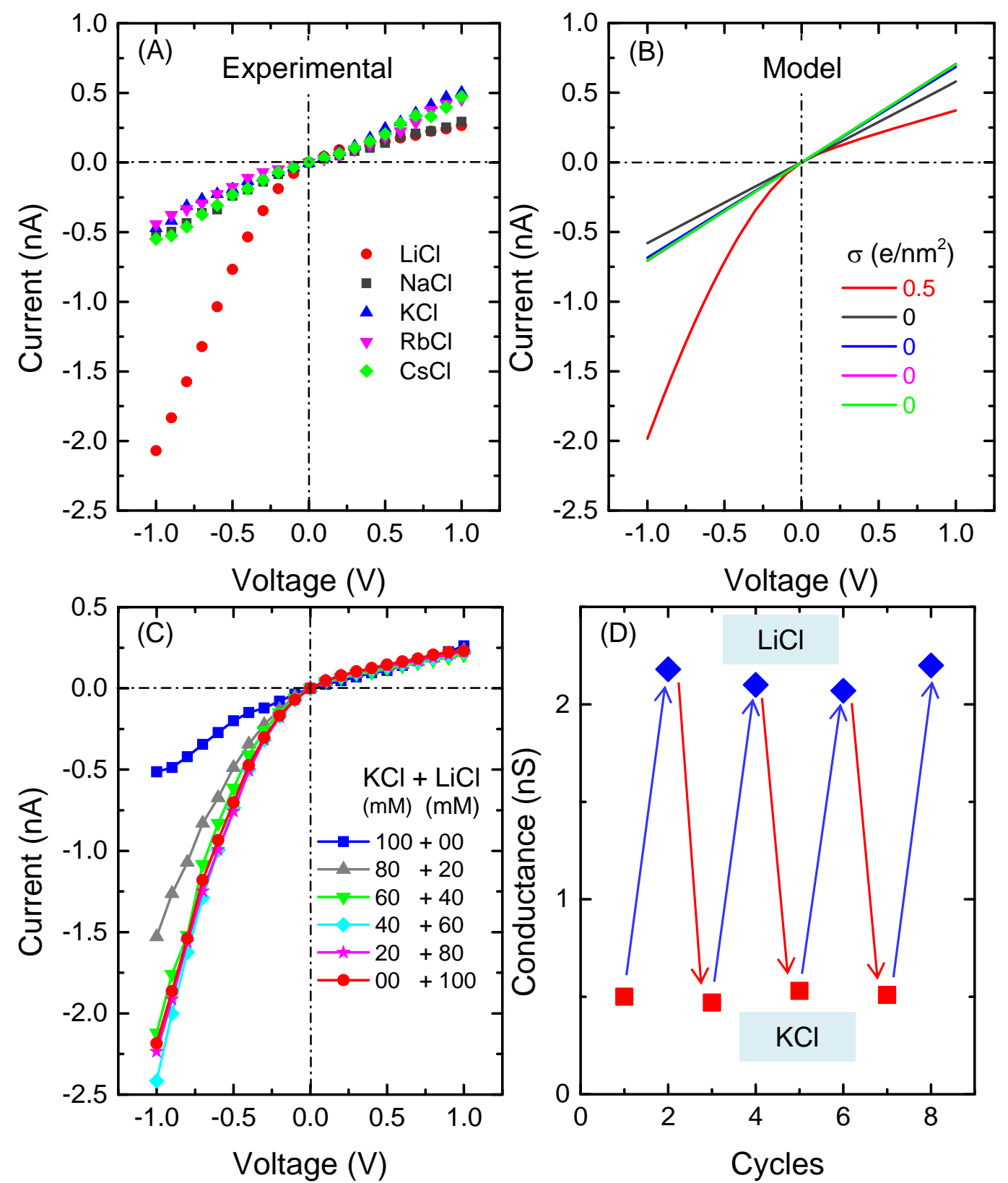

Figure 5. (A) $I-V$ characteristics of a second modified pore exposed to different alkali cation (100 mM, pH 6.5) solutions separately. (B) Model calculations corresponding to the experimental data. (C) $I-V$ characteristics of the this pore exposed to different fractions of $\mathrm{KCl}$ and $\mathrm{LiCl}$ solutions keeping the ionic strength $(100 \mathrm{mM})$ constant of the electrolyte. (D) The conductance obtained at $V=-1 \mathrm{~V}$ after several measuring cycles on exposing the modified pore to $\mathrm{KCl}$ and $\mathrm{LiCl}$ solutions, alternatively. 


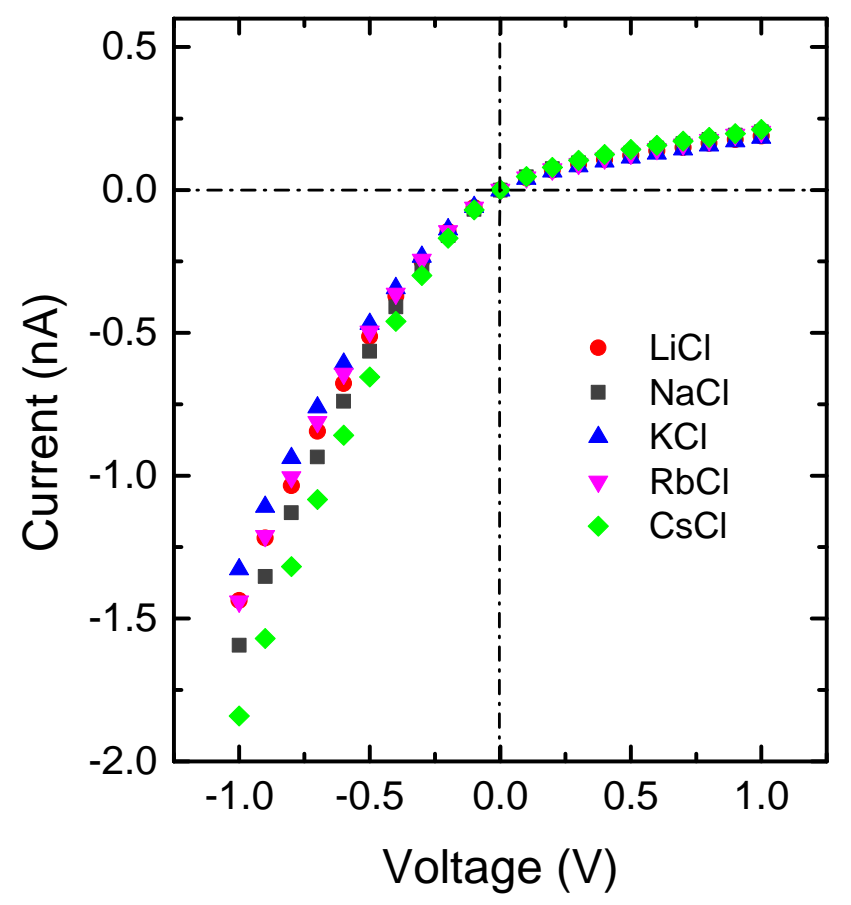

Figure 6. $I-V$ curves of the modified pore exposed to different alkali metal chloride (100 mM, pH 3.5) solutions. 
TOC graphics

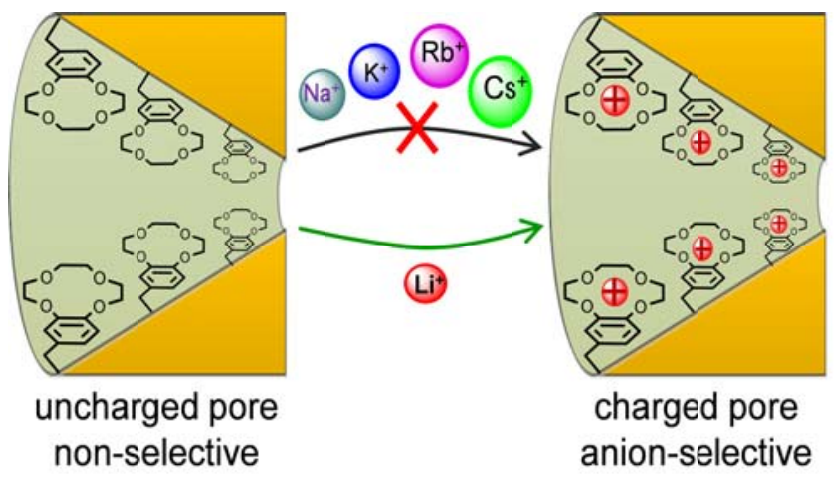

